\title{
Uma causa pouco habitual de diarreia
}

\author{
An unusual cause of diarrhea
}

\author{
Romeu Pires, Cristiana Batouxas, Tiago Loza, Prudência Vaz \\ Serviço de Medicina Interna. Unidade local de Saúde do Nordeste. Hospital de Bragança. Bragança. Portugal.
}

\begin{abstract}
Resumo
A diarreia crónica é uma manifestação comum de doenças gastrointestinais que pode estar associada às mais diversas etiologias. Estima-se que a sua prevalência nos países ocidentais seja de $4-5 \%$. A sua abordagem diagnóstica é complexa atendendo à multiplicidade de causas subjacentes. Os autores apresentam o caso clínico de um paciente admitido com quadro de diarreia com 6 meses de evolução e perda ponderal de $18 \mathrm{Kg}$ nesse período, cuja investigação diagnóstica revelou tratar-se de um caso de doença de Whipple.
\end{abstract}

Palavras chave. Whipple's disease; Diarreia crónica; Tropheryma whipplei

\section{Introdução}

A diarreia é uma manifestação clínica comum de doenças do foro gastrointestinal que pode ser definida em termos de volume, frequência e características das dejecções. Para a maior parte dos pacientes, o conceito de diarreia assenta na consistência das dejecções, que é determinada pela capacidade de retenção de água pelas fezes, o que na prática clínica é difícil de determinar. Outros critérios, tais como um número superior a 3 dejeções ou um peso de dejecções superior a $200 \mathrm{~g} /$ dia são meios alternativos de definição da diarreia mas que carecem de especificidade pela variabilidade que apresentam na população assim como pela influência dos hábitos alimentares. Assim, em termos pragmáticos, a diarreia é a passagem anormal de fezes moles ou líquidas, mais de três vezes ao dia e/ou de volume de fezes maior do que $200 \mathrm{~g} / \mathrm{dia}$, sendo considerada crónica quando os sintomas persistem para além das 4 semanas. Estima-se que a prevalência da diarreia crónica seja 4 a 5\% nos países ocidentais ${ }^{1}$.

Na prática clínica, uma miríade de patologias gastrointestinais cursam com diarreia crónica (tabela 1), podendo cursar com síndromes de má absorção e consequente défices nutricionais e má nutrição. Nos países subdesenvolvidos, é frequentemente causada por infecções bacterianas crónicas, micobacterianas ou parasitárias. Nos países desenvolvidos, a doença inflamatória intestinal, o síndrome de intestino irritável, as síndromas de má absorção e infecções crónicas são as causas mais comuns. 0 tratamento da diarreia crónica deve ser dirigido à causa e à correção dos distúrbios hidrolectrolíticos e nutricionais ${ }^{1,2}$.

\section{Caso clínico}

Homem de 78 anos, reformado da construção civil, natural de Portugal e residente na Alemanha desde os 20 anos. Tem antecedentes de hipertensão arterial essencial, diabetes mellitus tipo 2, cardiopatia isquémica, colecistectomia eletiva por litíase vesi-

\section{Abstract}

Chronic diarrhea is a common manifestation of gastrointestinal diseases that may be associated with many different etiologies. It is estimated that its prevalence in Western countries is $4-5 \%$. Its diagnostic approach is complex given the multitude of underlying causes. The authors present a clinical case of a patient admitted with diarrhea with 6 months of evolution and weight loss of $18 \mathrm{~kg}$ during this period, whose diagnostic investigation revealed that it was a case of Whipple's disease.

Keywords: Whipple's disease, Chronic diarrhea, Tropheryma whipplei

\author{
Colon \\ Neoplasia do cólon \\ Colite Ulcerosa \\ Doença de Crohn \\ Colite microscópica

\section{Intestino Delgado} \\ Doença celíaca \\ Doença de Crohn \\ Malabsorção de sais biliares \\ Deficiência de dissacaridáse \\ Small bowel bacterial overgrowth \\ Isquemia mesentérica \\ Enterite secundaria a radioterapia \\ Linfoma \\ Giardíase \\ Outras enteropatias secundárias (ex. Doença Whipple, amilóide, \\ linfangiectasia intestinal, tropical sprue)
}

\section{Pâncreas}

Pancreatite crónica

Carcinoma

Fibrose cística

\section{Endocrinológicas}

Hipertiroidismo

Diabetes mellitus

Hipoparatiroidismo

Doença de Addison

Tumor secretor de hormonas (VIPoma, gastrinoma, carcinóide)

\section{Outras}

Diarreia factícea

Ressecção cirúrgica do intestino delgado

Medicamentosas

Álcool

Neuropatia autonómica 
Figura 1. Terceira porção duodenal com lesões esbranquiçadas e mucosa congestiva

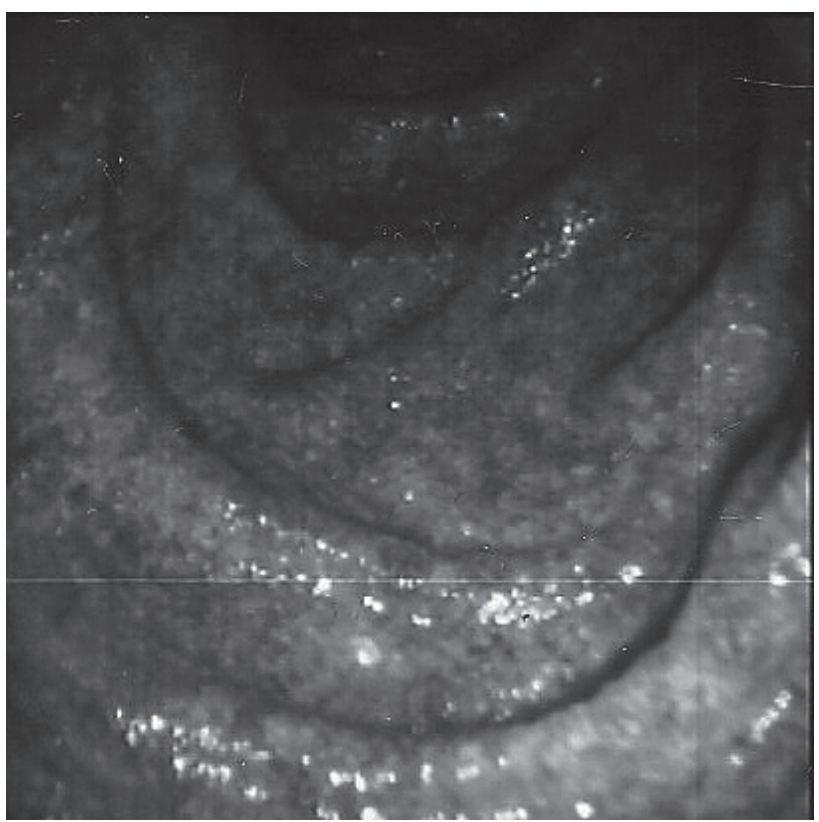

cular e cirurgia intestinal ao tubo digestivo não especificada. É medicado habitualmente com insulina basal, inibidor de enzima de conversão de angiotensina, análogo tiazídico, anti-agregante plaquetar e estatina, sem introdução de fármacos no último ano.

Um mês antes da sua admissão, esteve internado por desidratação associado a diarreia e febre. 0 doente apresentava diarreia com aproximadamente 6 meses de evolução, caracterizada por 8 a 10 dejecções líquidas por dia, sem sangue ou muco, com predomínio noturno, associado a astenia marcada e perda ponderal de aproximadamente $18 \mathrm{~kg}$ (25\% do peso corporal). Segundo 0 doente, a febre surgiu apenas nos últimos 2 dias, sem artralgias, náuseas, vómitos ou dor abdominal associados. 0 estudo analítico evidenciava de relevo leucocitose com neutrofilía, hiponatremia e hipocalémia. É tratado empiricamente com ciprofloxacina oral 1000 mg/dia e hidratação endovenosa. Após identificação de Ascaris lumbricoides ao exame parasitológico das fezes é associado albendazole 400 mg numa toma única por via oral. Teve melhoria clínica e analítica, tendo tido alta ao fim de 6 dias de internamento. Uma semana após o internamento, teve recidiva do quadro clínico inicial. Negava vómitos, dor abdominal, anorexia, artralgias, mialgias, uso de laxantes, consumo de água contaminada e de alimentos não pasteurizados ou mal cozinhados.

Ao exame objectivo apresentava temperatura axilar de $36.3^{\circ} \mathrm{C}$, tensão arterial de 101/56 mmHg, frequência cardíaca de 88 batimentos por minuto, eupneico com saturação de oxigénio de $96 \%$ em ar ambiente. 0 exame neurológico não apresentava alterações. A pele e as mucosas apresentavam-se pálidas e desidratadas, não se evidenciando lesões cutâneas, icterícia ou adenopatias palpáveis nas regiões cervicais, axilares e inguinais. A auscultação cardíaca e pulmonar eram normais. 0 abdómen apresentava cicatriz mediana e subcostal; à palpação era mole e depressível, sem massas ou órgãos palpáveis, indolor e sem sinais de irritação peritoneal.

0 estudo analítico, apresentava anemia microcítica e hipocrómica $(\mathrm{Hgb} 9.3 \mathrm{~g} / \mathrm{dL})$ com ferro sérico diminuído e ferritina normal.
Figura 2. Jejuno com congestão da mucosa e pontuados eritematosos e lesão aftosa

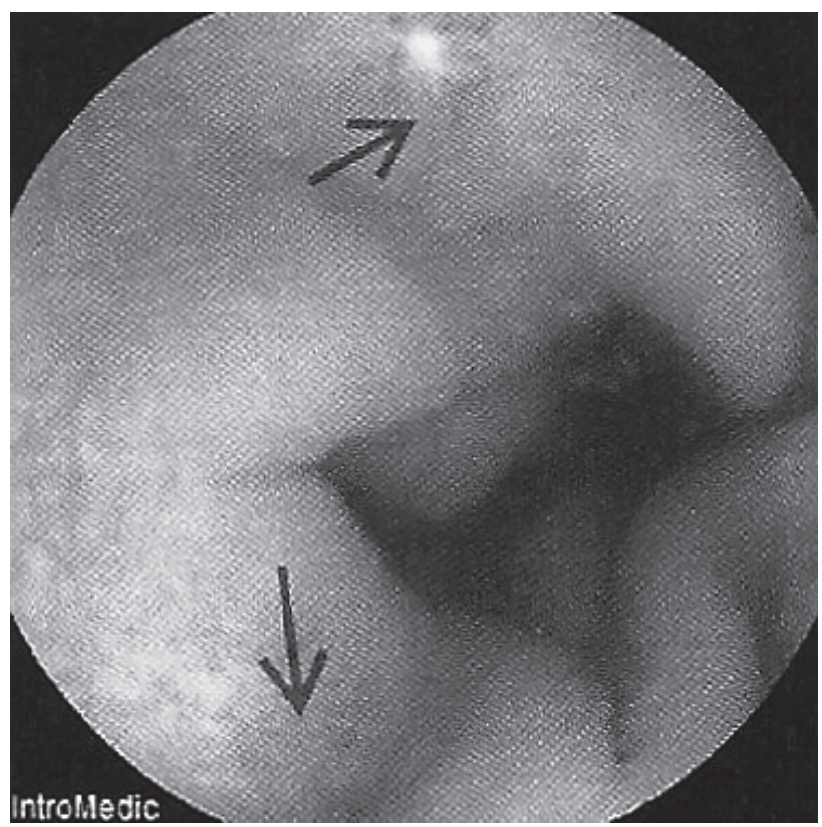

Vitamina B12 normal, ácido fólico diminuído [2.7 ng/mL (5.3$14.4 \mathrm{ng} / \mathrm{mL})]$. Leucocitose $\left(14.3 \times 10^{9} / \mathrm{L}\right)$ com neutrofilia $(12.2 \times$ $109 / \mathrm{L})$, proteína C reactiva [10.3 mg/dL $(<0.60)]$ e velocidade de sedimentação [90 mm/h (0-35)] aumentadas; Hiponatremia [ $\mathrm{Na}^{+}$ $132 \mathrm{mEq} / \mathrm{L}$ (134-145)] e hipocalémia [K+ $3.1 \mathrm{mEq} / \mathrm{L}$ (3.5-5.1)]. A função renal, tiroideia e hepática estavam preservadas. As serologias para HBV, HCV e HIV foram negativas; E o estudo microbiológico das fezes foi negativo. A tomografia axial computorizada abdominal e pélvica revelou fígado, baço, pâncreas e supra-renais com morfologia normal. Presença de múltiplas adenomegalias na raiz do mesentério e retroperitoneais, as maiores com $15 \mathrm{~mm}$. A endoscopia alta demonstrou esófago, estômago e bulbo duodenal sem alterações, verificando-se na segunda e terceira porção duodenais lesões esbranquiçadas com mucosa congestiva (figura 1), as quais foram biopsadas. A colonoscopia foi normal, não se evidenciando sinais de cirurgia prévia. Decidido realizar enteroscopia por cápsula para descartar a presença de outro tipo de lesões no restante tubo digestivo, que evidenciou lesões inflamatórias caracterizadas por congestão das mucosas, pontuados eritematosos e lesões aftosas em toda a extensão do jejuno e no íleo proximal. (figura 2 e 3). 0 exame histológico do fragmento duodenal (figura 4) descreve população histiócitica com marcação francamente positiva para a coloração PAS e negativa para a técnica de ZiehlNeelsen (ZN), sendo o quadro morfológico sugestivo de doença de Whipple (DW).

Perante o quadro clínico, os achados endoscópicos, a morfologia histológica e exclusão de envolvimento neoplásico e inflamatória do tubo digestivo, foi assumido o diagnóstico de síndrome de má absorção secundário a doença de Whipple. Iniciou antibioterapia com ceftriaxone 2 gramas uma vez por dia por via parentérica durante 14 dias. Ao quarto dia de antibioterapia, o número de dejecções começou a diminuir, verificando-se a sua remissão completa ao nono dia. Teve alta assintomático, a evidenciar ganho ponderal e recomendado manter antibioterapia com Trimetropimsulfametoxazol 160/800 mg 2 vezes por dia por via oral durante 1 
Figura 3 Íleo proximal com congestão da mucosa, pontuados eritematosos e lesão aftosa

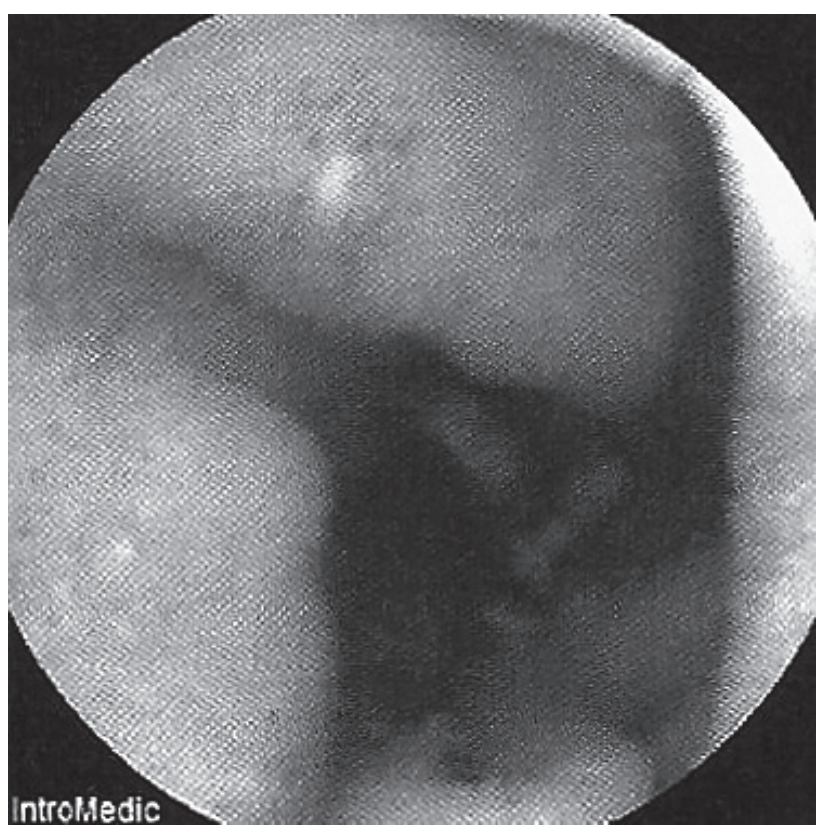

ano. 0 doente regressou à sua residência habitual na Alemanha, cumpriu esquema terapêutico prescrito e, voltou um ano após, apresentando melhoria franca do estado geral e sem recorrências da diarreia.

\section{Discussão}

A DW é uma doença infecciosa sistémica rara, de carácter crónico, causado por um bacilo gram-positivo, o Tropheryma whipplei (TW) pertencente à ordem das Actinomycetales, geralmente encontradas no solo ${ }^{3,4}$. Desde 1980, estima-se que a sua incidência anual ronde os 30 casos por ano $0^{4,5}$. Aproximadamente $80 \%$ dos indivíduos infectados são do género masculino, a maioria de raça caucasiana. A idade média na altura do diagnóstico é de 50 anos, podendo ocorrer em qualquer faixa etária. A hipótese de contagio por via oral é suportado pela identificação do DNA do TW nas fezes de indivíduos saudáveis e amostras de águas residuais ${ }^{3,4}$.

As manifestações clínicas são variáveis, com envolvimento particular do sistema digestivo, mas muitas vezes multisistémicas. A forma mais comum de apresentação é uma síndrome de má absorção, com diarreia e perda ponderal frequentemente associados a dor abdominal, febre, linfadenopatias periféricas e abdominais ${ }^{3,5,6}$. 0 envolvimento cardíaco na DW pode afectar qualquer estrutura, estando essencialmente descritos casos de endocardite, com a maioria diagnosticada após análise das válvulas ressecadas ${ }^{7,89}$. A sintomatologia osteoarticular está presente em cerca de 90\% dos casos, geralmente precede 0 diagnóstico em cerca de 10 anos e caracteriza-se por oligo ou poliartralgias simétricas, migratórias, não destrutivas e seronegativas. 0 sistema nervoso central é envolvido em cerca de $45 \%$ dos casos de DW, podendo surgir de forma isolada em $5 \%$ dos doentes. As manifestações neurológicas surgem de forma insidiosa sob a forma de distúrbios cognitivos, combinado ou isoladamente com alterações psiquiátricas ${ }^{3,5,6,9}$.

A endoscopia digestiva alta com biópsias do intestino delgado é o exame de diagnóstico de eleição. Os achados endoscópicos mais comuns são o espessamento das pregas da mucosa, com exsudados esbranquiçados confluentes alternando com erosões e áreas de friabilidade ${ }^{10}$. Em termos histológicos, a infiltração da lâmina própria do intestino delgado por macrófagos contendo no seu interior estruturas baciliformes, PAS positivas e resistentes à diástase, acompanhadas de dilatação linfática são aspectos típicos na DW, mas não patognomónicos, uma vez que, embora raro, poderem também ser encontrados em doentes com infecções provocadas por Mycobacterium avium, Rhodococcus equi, Bacillus cereus, Corinebacterium ou o Histoplasma. A identificação de sequências do genoma da bactéria presentes em tecidos ou fluídos orgânicos por técnicas de PCR são um método de elevada sensibilidade e especificidade, reservado em situações atípicas em que o diagnóstico não é confirmado por histologia. A microscopia electrónica é considerada o exame "gold standard" para a confirmação diagnóstica, contudo sendo um exame dispendioso, complexo e nem sempre acessível é utilizado para esclarecer os casos em que a histologia ou as técnicas de PCR são duvidosas ${ }^{5,6}$.

Previamente ao uso de antibióticos no tratamento da DW, esta era uniformemente fatal. Não existe um consenso global relativamente ao tipo e duração do esquema terapêutico nem da antibioterapia a utilizar. Hoje em dia, sabe-se que 0 TW é intrinsicamente resistente às fluoroquinolonas ${ }^{11}$. Com a antibioterapia adequada a maioria dos doentes evolui favoravelmente com remissão da diarreia, artralgias e febre no período de uma semana e subsequente ganho ponderal. Embora o tratamento inicial se revele eficaz, as recidivas podem ocorrer vários anos após a suspensão da antibioterapia, sendo mais frequentes nos doentes com envolvimento do SNC e naqueles tratados com um único tipo de antibiótico ou com um antibiótico que não ultrapassa a barreira hemato-encefálica. Apesar da falta de consenso, a maioria dos autores recomendam ceftriaxone endovenoso 2 gramas uma vez por dia ou penicilina $G$ endovenosa 2-4 milhões de Unidades de 4/4 horas durante 2 a 4 semanas, seguido de trimetropin-sulfametoxazol $960 \mathrm{mg} 2$ vezes por dia por via oral durante um ano $0^{3,6,9}$.

No presente caso clínico, a melhoria clínica e transitória verificada no decurso do primeiro internamento, pode ser explicada pelo tratamento da infecção pelo Ascaris lumbricoides com 0 albendazol e pelo uso de ciprofloxacina em doses elevadas. Apesar do TW apresentar características que 0 tornam intrinsecamente resistente às quinolonas, estudos de susceptibilidade in vitro demonstram uma supressão do número de cópias de DNA do TW com concentrações relativamente elevadas de ciprofloxacina ${ }^{11}$. A desadequação antibiótica e a curta duração do tratamento devem ter estado na 
Figura 4. Coloração PAS positiva de fragmento duodenal (ampliação 40x)

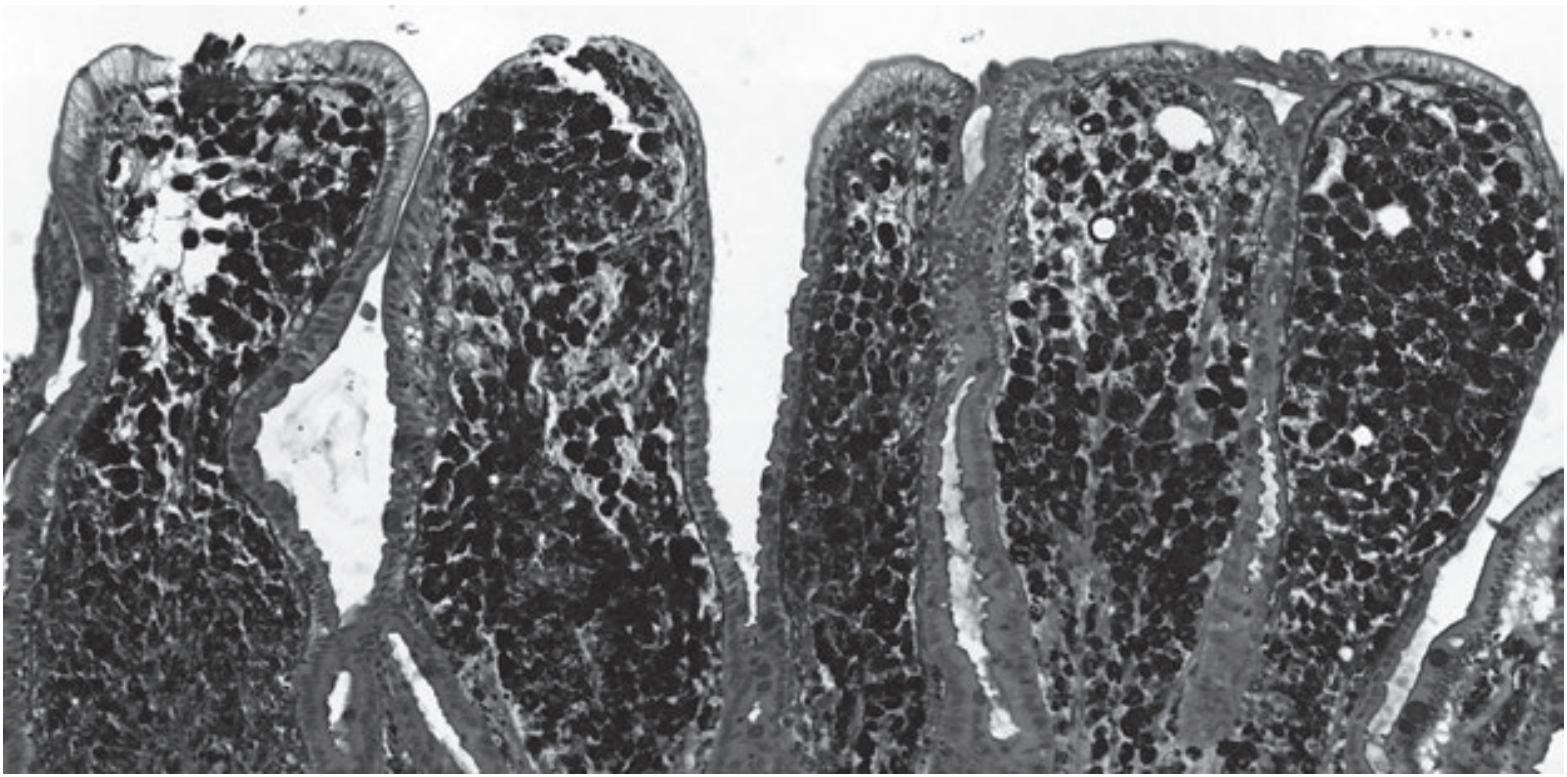

origem da recorrência da sintomatologia. 0 doente apresentava apenas sintomas constitucionais e envolvimento gastrointestinal da doença, na forma de diarreia crónica. Nestas situações, quando o envolvimento do tubo digestivo pela DW está presente, 0 diagnóstico é geralmente simples, uma vez que a maioria dos doentes apresentam envolvimento proximal do intestino, facilmente acessível à biópsia. Os achados histológicos revelam uma coloração intensa dos macrofágos espumosos em toda a lâmina característico da DW e, que do ponto de vista prático, pode ocasionalmente ser confundido com o envolvimento pelo Mycobacterium avium em pacientes com o síndrome de imunodeficiência adquirida. De qualquer forma, a distinção é feita pela técnica de ZN, que é positivo em pacientes infectados com o $M$. avium e negativo em pacientes com DW ${ }^{12}$. As amostras recolhidas neste caso, não foram suficientes para confirmar especificamente a presença do TW quer por PCR ou microscopia electrónica. Perante a história e manifestações clínicas, os achados histológicos e a ausência de um diagnóstico alternativo plausível foi assumido o diagnóstico de DW. A resposta favorável à terapêutica dirigida, com resolução sustentada da diarreia e dos sintomas constitucionais funcionaram como prova terapêutica positiva, não tendo sido possível manter seguimento e reavaliação a longo prazo.

\section{Bibliografia}

1. P Thomas, A Forbes; J Green, P Howdle, R Long, R Playford, MSheridan, R Stevens, R Valori, J Walters, GM Addison, P Hill, G Brydon: Guidelines for the investigation of chronic diarrhoea, 2nd edition; Gut 2003;52(Suppl V):v1-v15.

2. J Murray, A Rubio-Tapia: Diarrhoea due to small bowel disease. Best Pract Res Clin Gastroenterol. 2012;26(5);581-600.

3. D Seguy: La maladie de Whipple; Gastroenterol Clin Biol 2007; 31: 729-739.

4. J Bures, M Kopacova, T Douda, J Bartova, J Toms, S Rejchrt, I Tacheci: Whipple's disease: Our own experience and review of the literature. Gastroenterol Res Pract. 2013;2013:478349.

5. F Fenollar, X Puéchal, D Rauolt: Whipple's Disease; N Engl J Med 2007; 356:55-66.

6. A Carneiro, P Lima, I Barbosa, C Chaves: Doença de Whipple Um Desafio Diagnóstico; Acta Med Port 2004; 17:481-486.

7. W Geissdörfer, V Moos, A Moter, C Loddenkemper, A Jansen, R Tandler, A Morguet, F Fenollar, D Raoult, C Bogdan, T Schneider: High frequency of Tropheryma whipplei in culture-negative endocarditis. J Clin Microbiol. 2012;50(2):216.

8. F Fenollar, H Lepidi, D Raoult: Whipple's Endocarditis: Review of the Literature and Comparisons with Q Fever, Bartonella Infection, and Blood Culture-Positive Endocarditis. Clinical Infectious Diseases 2001;33:1309-16.

9. S Misbah, N Mapstone: Whipple's disease revisited. J Clin Pathol 2000;53:750-755.

10. G Gay, M Delvaux, M Frederic: Capsule endoscopy in non-steroidal anti-inflamatory drugs-enteropathy and miscellaneous, rare intestinal diseases; World J Gastroenterol 2008 September 14; 14 (34): 5237-5244.

11. F Masselot, A Boulos, M Maurin, JM Rolain, D Raoult: Molecular evaluation of antiobiotic susceptibility: Tropheryma whipplei paradigm; Antimicrob Agents Chemother 2003;47: 1658-1664;

12. W Dobbins: The diagnosis of Whipple's disease. N Engl J Med. 1995 Feb 9;332(6):390-2. 